Available Online at ESci Journals

International Journal of Educational Studies

ISSN: 2312-458X (Online), 2312-4598 (Print)

http://www.escijournals.net/IJES

\title{
IMPACT OF SCHOOL FEEDING PROGRAMME ON LEARNERS' ACADEMIC PERFORMANCE IN MLUNDUZI WARD, TANZANIA
}

\author{
Shabani N. Maijo \\ Institute of Adult Education, Department of Adult Education and Continuing Studies, Tanzania.
}

\begin{abstract}
A B S T RA C T
This study conducted to assess the impact of school feeding programme on pupil's academic performance in Mlunduzi ward, Tanzania. The cross-sectional survey design was used for this study. This study was equally qualitative and quantitative in nature. A questionnaire was administered to capture the impact from 96 respondents in four randomly selected primary schools in Mlunduzi ward. Focus Group Discussion (FGD) was employed to complement the questionnaires. A checklist was used to validate data from learners and teachers through the focus group discussion. The data were analyzed using descriptive statistics. The results expose that school feeding programme had shown significant impact on learner's academic performance. The analysis has indicated that the school feeding programme had increased examination performance, helped to get learners into school, enhancing enrolment and reducing absenteeism. The assessment of examination scores in the period before and during school feeding programme had shown that learners got better in an examination during the school feeding programme than before. The study recommends that in practice school feeding programme is difficult interventions; it can be with advantages if the policy makers and implementers can benefit from a careful examination of the programme by involving local communities than depending on donors so as to ensure sustainability of the programme.
\end{abstract}

Keywords: Impact, school feeding programme, learners, academic performance, Tanzania.

\section{INTRODUCTION}

School Feeding Programme (SFP) is a crucial ingredient in the human's body growth and cognitive development. Children need a reliable food supply to meet the metabolic supplies of body growth and brain development (Akanbi, 2013). Setting priority to school feeding programme is fundamental involvement in reducing the short- term hunger, providing learner's cognitive function by and enhancing the learning environment (Lawson, 2012). The school feeding programme would enable learners to increase their regular attendance in order to improve their academic performance. The study carried in Malawi had been indicated that school feeding programme had an effect on learner's enrollment and attendance. The enrollment increased up to $5 \%$ and improvement of attendance up to $36 \%$ (WFP, 1996).

It is believed that the short term hunger in the classroom

\section{* Corresponding Author:}

Email: sdyson@dmu.ac.uk

(C) 2018 ESci Journals Publishing. All rights reserved. may affect the academic performance of learners. Further, it has been suggested that school feeding programme if provided properly did raise school enrollment and increased school attendance (Ahmed, 2004). School feeding programme greatly promotes the learning style of learners in schools. It is one of the key interventions for promoting learning to learners in the areas of food insecurity. This can motivate learners to concentrate and learn better so as to improve learning capacity and performance. Therefore, it is apparent that the supply of food to learners in primary schools' level had increased school attendance and reduced dropout among the learners in the community schools in Tanzania (Malila, 2015). Learners involved in the school feeding programme has access to enhancing their academic performance since it enabled them to attend school frequently and learn more efficiently (Yunusa et al., 2012). Meyers et al. (2013) established that children from elementary schools who participated in school breakfast programme had shown significant growth in academic function. 
However, several kinds of literature have associated the school feeding programme with learner's academic performance (Chepkwony et al., 2013) (Taylor and Ogbogu, 2016). School feeding is the supply of food to children through schools (Adrogue and Orlicki, 2013). It has been established that giving learners a daily meal at school might improve their academic achievement in several ways; by increasing attendance, improving certain cognitive function and attention to learning (Oyefade, 2014). The purpose of school feeding programme usually differs includes alleviating short term hunger, enhancing health (Allen and Gillespie, 2001), school attendance (Caldes and Ahmed, 2004) and cognitive (Levinger, 1986). The presence of short term hunger in some schools is a major challenge that alters academic performance. However, supplying food support to primary schools' children in constantly food insecure areas aim to diminish short term hunger in classrooms. The purpose is to improve learning performance among learners. Hence, the impact of school feeding programme had investigated empirically that learners who get food in school have shown the increase of scores than those who have not involved in the programme (Sandler, 2011).

In Kenya, the school feeding programme to public schools had shown to increase academic performance compared to schools with no school feeding programme (Chepkwony et al., 2013). Further, the study carried in the private schools in Nigeria observed that providing food to learners during school time had contributed to learner's attention and academic performance. The supplied food in schools had increased school attendance and reduced dropout among the community schools. In Bangladesh a programme of school-based food distribution had increased attendance by $20 \%$ compared a $2 \%$ decline of non-feeding school (Ahmed and Billah, 1994). In Jamaica, it was indicated that the learners aged between 7-11 years in food insecure family unit scored lower in arithmetic test compared those supported by school meals. The school feeding programme significantly had increased learners performance. Adelman et al. (2008) pointed out that literacy scores had decreased to a sample of students who received home food than students who were received school food.

In the early 2000s, the Tanzanian government introduced the Primary Education Development Programme (PEDP) with the purpose of increasing access to education and improving the teaching and learning infrastructures. The programme stressed on free primary education. Enrollment and attendance of learners in schools was not proportionally appended to the programme. To support the objectives of the programme, the government introduced the school feeding programme at primary school level in the regions of food insecurity. Therefore, a reason to conduct this study was to assess the impact of school feeding programme on learners' academic performance. Mpwapwa district like other districts in Tanzania, the learners are affected by the short term hunger in classrooms. The district has been providing food to learners since 2006 under the support from the World Food Programme (WFP). Parents have been contributing to push their children to attend regularly in schools. School feeding programme did raise school enrollment, reduce the possibility of dropout from school and increase school attendance (Mamba, 2014). School feeding programmes in primary school has been noted as the significant intervention in increasing learners' enrollment, attendance and reducing the possibility of dropout. Feeding children through school would impact academic performance in Tanzania. Therefore, the researcher sought to assess the impact of school feeding programme on learners' academic performance and to compare the learners' performance before and after school feeding programme amongst learners in Mlunduzi Ward, Tanzania.

\section{MATERIAL AND METHODS}

The study adopted a cross-sectional survey design. The design used because it allowed the study to collect data at one point in time. Also, the design allowed assessment on the impacts of school feeding programme on learner's academic performance. The survey was appropriate because enable the researcher to use different methods to collect data. The survey was carried in four (4) selected schools. The target population of the study included learners and teachers from the four schools in Mlunduzi ward. This category of respondents provided the true measure of the sample study due to having knowledge of the school feeding programme and learners' classroom achievements. Ninety-six (96) learners registered in four primary schools were taken by using simple random sampling technique. Twentyeight (28) teachers were taken purposively as key informants of the study.

The self-structured questionnaire with close-ended 
questions was used to collect data in the study. The instrument was developed specifically for the learners. The type of questionnaires produce answers which can be subjected to statistical analysis (Cohen et al, 2004). The focus group discussion by using the checklist was employed for teachers and learners. The checklist was designed mainly to examine the impact of school feeding programme on academic performance.

The period of two months was used to distribute and collect the questionnaire from respondents. Respondents filled the questionnaire provided. An interview was carried while the respondents could ask for clarification on what was written in the questionnaire. The researcher reviewed the secondary data in the scorebook to compare the result of learners in the period before and after the school feeding programme.

The collected data was analyzed using Statistical Package for Social Sciences (SPSS) whereby descriptive statistics presented in terms of percentages, frequencies. Chi-square test was used to test the correlation of the school feeding programme and learners' academic performance. Independent variables namely increase the number of teachers, attendance, learning and teaching materials, food in school, scores and enrolment were used in this study when other factors remain constant. Documentation information score were used to correlate with learners' academic performance.

\section{RESULTS}

Characteristics' of Respondents: The analysis as summarized in Table 1 revealed that 23 (23.9\%) were from Chinyika primary school, 24 (25\%) from Chinyangh'uku primary school, 25 (26.2\%) from Mlunduzi primary school, and 24 (25\%) were from Chaludewa primary school.

Table 2 shows the gender distribution of respondents that $50(52.1 \%)$ were males and were 46 (47.9\%) female. Also, the study revealed the age of respondents with the age mean of 13.04 .

Teachers in this study were treated as the key informants, the study findings as indicated in Table 3 showed that $19(66 \%)$ were male and 9 (34\%) were female.

On the case of the education level of respondents (teachers), the data as shown in Table 4 signifies that 26 (93.3\%) had completed tertiary education and $9(6 \%)$ had completed secondary education.
Table 1. Frequency distribution of respondents with respect to school.

\begin{tabular}{lcc}
\hline School & Frequency & Percent \\
\hline Chinyika & 23 & 23.9 \\
Chinyangh'uku & 24 & 25 \\
Mlunduzi & 25 & 26.2 \\
Chaludewa & 24 & 25 \\
\hline Total & 96 & 100
\end{tabular}

Source: Research Data (2018).

Table 2. Frequency distribution of respondents (learners) with respect to gender.

\begin{tabular}{lcc}
\hline School & Frequency & Percent \\
\hline Male & 50 & 52.1 \\
Female & 46 & 47.9 \\
\hline Total & 96 & 100
\end{tabular}

Source: Research Data (2018).

Table 3. Frequency distribution of teachers by gender

\begin{tabular}{lcc}
\hline School & Frequency & Percent \\
\hline Male & 19 & 66 \\
Female & 09 & 34 \\
\hline Total & 96 & 100
\end{tabular}

Source: Research Data (2018).

Table 4. Frequency distribution of teachers by education level.

\begin{tabular}{lcc}
\hline School & Frequency & Percent \\
\hline Tertiary & 26 & 93.3 \\
Secondary & 09 & 6.7 \\
\hline Total & 96 & 100 \\
\hline
\end{tabular}

Source: Research Data (2018).

Impact of School Feeding Programme on learners' Academic Performance: To determine the impact of school feeding programme on learners' academic performance, the correlation coefficient analysis was done. The result shows that the school feeding programme had a positive impact on learners' academic performance. The obtained results from the analysis (as indicated in Table 5) showed that there is a negative correlation between learners' academic performance, attendance $(\mathrm{r}=-0.478, \mathrm{p}<0.000)$, teaching and learning materials $(r=-0.550, p<0.001)$ at a significance level of 0.00 in the coefficient determination of $\left(R^{2}=0.229\right)$. 
Table 5. Impact of school feeding programme on learners' academic performance.

\begin{tabular}{cccccc}
\hline & \multicolumn{3}{c}{ Yi } & R2 $=0.229$ \\
\hline Xi & B & e & Beta & t-value & Sig. \\
\hline Attendance & -0.478 & 0.091 & -0.478 & -5.280 & $0.000\left(^{* *}\right)$ \\
Enrolment & 1.875 & 0.186 & 0.301 & 10.083 & $0.001^{* *}$ \\
T/L materials & $0-.550$ & 0.094 & 0.550 & -5.848 & $0.000^{* * *}$ \\
School feeding & 0.061 & 0.056 & 0.101 & 1.087 & $0.280^{* *}$ \\
Examination scores & 0.012 & 0073 & 0.015 & 0.171 & 0.864 \\
\hline
\end{tabular}

Source: Research Data (2018).

However, the school feeding programme has reported having a positive significant impact on learners' academic performance in enrollment and examination scores. The results as indicated in Table 6 clearly showed the significant impacts of school feeding programme on learners' academic performance. The results analysis found that $67.7 \%$ of learners reported the school feeding programme to increased examination performance, $22.9 \%$ reported on the increased of school attendance and $9.4 \%$ said the programme had reduced absenteeism among learners. Similarly, the results as reported by teachers showed that school feeding programme has motivated learners' to learn by $8.3 \%$ than it was reported in the previous years. In addition, results indicate that school feeding program had improved academic performance by increasing number of learners passing standard seven examinations to join secondary school education by $31 \%$ (from 51.5 to $83 \%$ ) in 2013 to 2015.

Table 6. Impacts of the school feeding programme.

\begin{tabular}{lcc}
\hline \multicolumn{1}{c}{ Variables } & Frequency & Percentage \\
\hline Increased exam performance & 65 & 67.7 \\
Increased attendance & 22 & 22.9 \\
Reduced absenteeism & 9 & 9.4 \\
\hline Total & 96 & 100 \\
\hline
\end{tabular}

Source: Research Data (2018).

Table 8. National Examination before SFP (2010-2016).

\begin{tabular}{lcccccc}
\hline \multirow{2}{*}{ Name of School } & \multicolumn{7}{c}{ Year } \\
\cline { 2 - 7 } & 2012 & 2013 & 2014 & 2015 & 2016 & Total \\
\hline Mlunduzi & - & - & - & - & - & - \\
Chinyika & 4 & 4 & 14 & 12 & 8 & 42 \\
Chinyangh'uku & 6 & 4 & 3 & 6 & 9 & 28 \\
Chaludewa & 12 & 5 & 5 & 2 & 10 & 34 \\
\hline Total & 22 & 9 & 22 & 29 & 27 & 109 \\
\hline
\end{tabular}

Source: Research Data (2018). 
Table 9: Average Scores before SFP in 2017.

\begin{tabular}{cccccc}
\hline No & Math & English & History & Science & Kiswahili \\
\hline 1 & 70 & 56 & 70 & 30 & 60 \\
2 & 65 & 65 & 60 & 50 & 60 \\
3 & 65 & 40 & 50 & 50 & 50 \\
4 & 45 & 50 & 50 & 60 & 70 \\
5 & 40 & 50 & 60 & 50 & 50 \\
6 & 25 & 60 & 40 & 30 & 80 \\
7 & 43 & 86 & 45 & 50 & 50 \\
8 & 56 & 47 & 70 & 40 & 40 \\
9 & 60 & 50 & 40 & 60 & 70 \\
10 & 60 & 65 & 30 & 43 & 50 \\
\hline
\end{tabular}

Source: Research Data (2018)

For further analysis of data the scores marks of learners' in five subjects namely Mathematics, English, History, Kiswahili and Science were considered. The reason for this was that the study focused on examining the impact of school feeding programme on learners' academic performance (examination score performance). The analysis of the study shows that the average score marks of the five subjects was at $50 \%$ with the standard deviation of 10.4 before the school feeding programme.

Table 10: Average Scores after SFP in 2017.

\begin{tabular}{cccccc}
\hline No & Math & English & History & Science & Kiswahili \\
\hline 1 & 70 & 80 & 70 & 70 & 80 \\
2 & 80 & 65 & 60 & 70 & 60 \\
3 & 65 & 60 & 70 & 50 & 60 \\
4 & 70 & 50 & 50 & 90 & 70 \\
5 & 70 & 50 & 89 & 50 & 70 \\
6 & 70 & 60 & 70 & 70 & 80 \\
7 & 70 & 86 & 70 & 50 & 50 \\
8 & 56 & 80 & 70 & 60 & 80 \\
9 & 60 & 50 & 40 & 60 & 70 \\
10 & 60 & 65 & 80 & 43 & 50 \\
\hline
\end{tabular}

Source: Research Data (2018).

The analysis of examination performance after school feeding programme (as indicated in Table 10) shows that score marks of the same subjects with an average of $76 \%$ after during the school feeding programme. Hence, the results show that the school feeding programme has contributed to increasing learners' examination performance with the increase in score marks compared to 2010. The analysis from teachers (key informants) showed that the school feeding programme had influenced the pass rate of final examinations.

\section{DISCUSSION}

School feeding programme had a significant impact on the learners' academic performance. The major finding of the study implies that school feeding programme had improved examination results by increasing the number of learners who passed standard seven examinations to join secondary school by 31\% in 2016. The learners' performance is actually determined by the number of factors that are a direct or indirect influence on academic performance. The study supports that supplying food at school during school days enhances school attendance directly to the learner. The impact of school feeding indicates to function both through the improvements of the school environment, enrollment and attendance in better learning and reduce the dropout rate in school. The average enrollment rate had increased from $82.1 \%$ in 2000 to $98.32 \%$ in 2009 . Also, the studies conducted by Ahmed (2004) address some of the potentially adverse impact of SFP on enrolment in relation to academic performances. Instinctively, the positive impacts on academic performances would require that the learning environment remains constant or improves when enrollment increases.

Therefore, unless other factors such as adequately trained teachers, learning materials and adequate physical facilities are available to school feeding programme would not improve learners' academic performance.

Constantly, the school feeding in developing countries was connected with increased school enrollment, regular attendance, lower dropout rates and higher success rates on national examinations. The findings of the study also showed that the school feeding programme has increased attendance among learners. However, it has been reported that school feeding was effective in increasing enrollment and attendance in primary schools, but academic performance gauged by the standardized test was low than in a school that did not engage from the programme.

The results of the study also indicated that the school feeding programme has increased pass rate in the national examination. The difference in performance before and after school feeding has contributed by the increase in the number of primary schools in the 
countryside. Oyafade (2014) pointed out that the school feeding programme is suitable for learners' attendance as motivation in learning, but the academic performance is a combination of factors.

\section{STUDY IMPLICATION}

The study provides insights to policy makers and planners on the need for school feeding programme to learners in school. In practice, the school feeding program is a complex and expensive intervention. There is a need to stakeholder to improve learners' academic performance despite the school feeding programme. To make it sustainable the government through district councils is advised to engage in planning and educating for community members on cost sharing of the school feeding program.

\section{ACKNOWLEDGEMENT}

The author expresses sincere thanks to all who supported the implementation of the study. Also, special thanks should go to the students and teachers who involved in the study.

\section{REFERENCES}

Adelman, S., D. Gilligan and K. Lehrer. 2008. How effective are food for education programs?: A critical assessment of the evidence from developing countries. International Food Policy Research Institute.

Adrogue, C. and M. E. Orlicki. 2013. Do In-School Feeding Programs Have an Impact on Academic
Performance and Dropouts? The Case of Public Schools in Argentina. education policy analysis archives, 21: 50.

Ahmed, A. U. 2004. Impact of Feeding Children in School: Evidence from Bangladesh. The United Nations University International Food Policy Research Institute, Washington, D.C.

Chepkwony, B. C., L. J. Kosgei and B. M. Kariuki. 2013. School feeding program and its impact on academic achievement in ECDE in Roret Division, Bureti District in Kenya. Journal of Emerging Trends in Educational Research and Policy Studies, 4: 407-412.

Mamba, P. G. 2014. Comparative perception of the Home Grown School Feeding Program versus the NonHome Grown School Feeding Program on aspects of learners' performances and food security in the Lubombo region (Unpublished) Master's thesis, University of Pretoria, Pretoria, South Africa.

WFP. 1996. World Food Programme. Food and Agriculture Organization, United Nations General Assembly, Rome, Italy.

Yunusa, I., A. M. Gumel, K. Adegbusi and S. Adegbusi. 2012. School feeding program in Nigeria: A vehicle for nourishment of pupils. The African Journal, 12: 53-67. 